\title{
Lower levels of interleukin-35 in patients with prophase of liver failure are associated with progression to liver failure
}

\author{
Li Chen, Wei Sun, Yan Wang, Xiaoping Huang, Jianhe Gan \\ Department of Infection, the First Affiliated Hospital of Soochow University, Suzhou, China \\ Contributions: (I) Conception and design: J Gan; (II) Administrative support: W Sun; (III) Provision of study materials or patients: L Chen, Y Wang; (IV) \\ Collection and assembly of data: L Chen; (V) Data analysis and interpretation: L Chen, X Huang; (VI) Manuscript writing: All authors; (VII) Final \\ approval of manuscript: All authors. \\ Correspondence to: Jianhe Gan. The First Affiliated Hospital of Soochow University, No. 188, Shizi Street, Suzhou 215000, China. \\ Email: ganjianhe@aliyun.com.
}

\begin{abstract}
Background Cytokines play critical roles in the inflammatory processes underlying liver failure. The relevance of interleukin-35 (IL-35), an anti-inflammatory cytokine, in liver failure remains uncharacterized. This study was conducted to investigate whether the IL-35 level in patients with prophase of liver failure (PLF) is associated with prognosis and the possible mechanism of immune regulation for IL-35.

Mothods: This retrospective study enrolled 42 patients with PLF at the Department of Infection, First Affiliated Hospital of Soochow University between January 2016 and December 2018. Thirty patients with hepatitis and 30 healthy controls were also enrolled. We divide patients with prophase of liver failure into improvement group who recovered quickly $(n=33)$ and deteriorate group who deteriorated to overt liver failure ( $n=9$ ). Serum IL-35 level was measured by enzyme-linked immunosorbent assay (ELISA). The ratio of regulatory $\mathrm{T}$ cells to T-helper type-17 cells (Treg/Th17) in peripheral blood was determined by flow cytometry.
\end{abstract}

Results: Serum IL-35 level was higher in patients with PLF who showed subsequent improvement than in patients with PLF who showed deterioration to overt liver failure. The Treg/Th17 ratio was higher in patients with PLF who showed improvement than in patients with PLF who developed overt liver failure. The serum IL-35 level and Treg/Th17 ratio were positively correlated in patients with PLF.

Conclusions: High serum IL-35 level is associated with better prognosis in patients with PLF.

Keywords: Liver failure; interleukin-35 (IL-35); Treg/Th17

Submitted Jun 04, 2021. Accepted for publication Jul 28, 2021.

doi: 10.21037/apm-21-1680

View this article at: https://dx.doi.org/10.21037/apm-21-1680

\section{Introduction}

Acute liver failure (ALF) is a rare but life-threatening medical condition associated with a high mortality rate (1). The annual incidence of ALF in the USA is around 1-6 cases per million persons, and the disease is responsible for $6 \%$ of liver-related deaths (2). The causes of ALF are varied and include drugs (such as paracetamol), viral and autoimmune hepatitis, and hepatic ischemia $(3,4)$. The characteristic pathological features of ALF are large-scale hepatic necrosis, substantial loss of hepatocytes, inflammation, and proliferation of bile duct structures (3). ALF is associated with numerous complications such as encephalopathy, coagulopathy, infection, hemodynamic instability, and kidney damage (2). Although a variety of treatment options are available, such as supportive medical therapy and artificial liver assist devices, liver transplantation is often the only hope of cure and is performed in almost $30 \%$ of ALF cases (4-6).

The prophase of liver failure (PLF) is associated with similar symptoms to those of ALF, including extreme fatigue and severe gastrointestinal symptoms such as anorexia, 
vomiting, and bloating. PLF is a critical stage, with some patients developing liver failure and others recovering rapidly. There is great interest in identifying biomarkers that would help to identify patients at risk of a poor prognosis. Numerous factors that predict the prognosis of liver failure have been identified, including several factors related to inflammation and the immune system (7-12).

Interleukin (IL)-35 is a recently discovered member of the IL-12 family of heterodimeric cytokines that is comprised of an IL-12 p35 subunit and an IL-27 $\beta$ subunit encoded by the Epstein-Barr virus induced-3 (EBI3) gene $(13,14)$. IL-35 is secreted by regulatory T (Treg) cells and other lymphocytes, and acts to suppress immune responses by inhibiting the differentiation of T-helper type-17 (Th17) cells and promoting the proliferation of Treg cells $(13,14)$. IL-35 has been implicated in a wide range of disorders including cancer, autoimmune diseases, inflammatory processes, infections, and sepsis (15). Furthermore, IL-35 has also been proposed to play an important role in liver injury. For example, preclinical and clinical research has suggested that IL-35 is involved in endotoxin-induced hepatitis (16), liver inflammation caused by infection with hepatitis $\mathrm{B}$ virus (HBV) or hepatitis $\mathrm{C}$ virus (HCV) (17-21), and hepatocellular carcinoma (22-24). However, little is known about the level of IL-35 during PLF and its relevance to prognosis. Therefore, the aim of the present study was to determine whether the IL-35 level in patients with PLF is associated with prognosis.

We present the following article in accordance with the STROBE reporting checklist (available at https://dx.doi. org/10.21037/apm-21-1680).

\section{Methods}

\section{Study design and study participants}

This retrospective study enrolled 42 consecutive patients diagnosed with PLF at the Department of Infection, First Affiliated Hospital of Soochow University, Suzhou, Jiangsu, China between 1 January 2016 and 30 December 2018. The diagnostic criteria for PLF were as follows: extreme fatigue with severe gastrointestinal symptoms such as anorexia, vomiting, and bloating; elevated total bilirubin (TBil) level $(51 \mu \mathrm{mol} / \mathrm{L} \leq \mathrm{TBil} \leq 171 \mu \mathrm{mol} / \mathrm{L})$ or a daily increase in TBil $>17 \mu \mathrm{mol} / \mathrm{L}$; bleeding tendency indicated from measurements of plasma thromboplastin antecedent (PTA: $40 \% \leq$ PTA $\leq 50 \%$ ) or international normalized ratio (INR: $1.5 \leq$ INR $\leq 1.6$ ). A further 30 patients with hepatitis but without liver failure were also recruited. In addition, 30 age- and sex-matched healthy control subjects were selected from the Medical Examination Center of the First Affiliated Hospital of Soochow University.

All procedures performed in this study involving human participants were in accordance with the Declaration of Helsinki (as revised in 2013). The study was approved by Medical ethics committee of the First Affiliated Hospital of Soochow University [No.: 175(2021)] and informed consent was taken from all the patients.

\section{Grouping}

PLF patients were divided into PLF with improvement and PLF with deterioration. Improvement was defined as reduced jaundice and shortened prothrombin time, while deterioration was progression to overt liver failure, which was defined as TBil $>171 \mu \mathrm{mol} / \mathrm{L}$ and either PTA $<40 \%$ or INR $<1.5$.

\section{Clinical data obtained at enrollment}

The following clinical parameters were measured at the time of enrollment: alanine transaminase (ALT) level, TBil level, PTA level, IL-35 level, Th17 cell count, and Treg cell count.

\section{Measurement of serum IL-35 level}

Serum IL-35 levels were determined in our institution's Clinical Laboratory Department by enzyme-linked immunosorbent assay (ELISA). Serum was obtained from peripheral venous blood samples and stored at $-70{ }^{\circ} \mathrm{C}$ until the time of the assay. The IL-35 level in each sample was measured using an ELISA kit (Xitang Biological Technology, Shanghai, China), in accordance with the manufacturer's instructions. Standards or samples were added to the microtiter plate, which had been pre-coated with an antibody specific for IL-35. Then, avidin conjugated to horseradish peroxidase was added to each microplate well, with incubation for 5 hours. Next, TMB (3,3',5,5'-te tramethylbenzidine) substrate solution was added to each well. The enzyme-substrate reaction was terminated by the addition of a sulfuric acid solution, and the color change was measured spectrophotometrically at a wavelength of $450 \pm 2 \mathrm{~nm}$. The concentration of IL-35 in the samples was then determined by comparing the optical density of the samples to a standard curve. 


\section{Analysis of Th17 cells}

Th17 cells were analyzed by flow cytometry. Fasting peripheral venous blood $(2 \mathrm{~mL})$ was drawn from each study participant in the morning. Peripheral blood mononuclear cells (PBMCs) were isolated by Ficoll density gradient centrifugation. A $2 \mathrm{~mL}$ volume of the PBMC suspension was added to each well of a 6-well plate and cultured for 4-6 hours at $37{ }^{\circ} \mathrm{C}$ in an atmosphere containing $5 \% \mathrm{CO}_{2}$. The cells were collected and divided into test and control samples $(100 \mu \mathrm{L}$ per tube), which were incubated at room temperature for 15 minutes with $10 \mu \mathrm{L} \mathrm{R}$-phycoerythrincyanin 5.1 (PC5)-conjugated anti-CD3 monoclonal antibody and $20 \mu \mathrm{L}$ R-phycoerythrin (PE)-conjugated anti-CD8 monoclonal antibody (BD Biosciences, San Jose, CA, USA). After 15 minutes of incubation with $100 \mu \mathrm{L}$ fixative solution (liquid A) at room temperature, $3 \mathrm{~mL}$ phosphate-buffered saline (PBS) was added. The mixture was centrifuged, and the supernatant was discarded. Cell perforation with $100 \mu \mathrm{L}$ membrane breaker (solution B) was used to enhance cytokine staining. Next, $20 \mu \mathrm{L}$ PE-labeled IL-17A (BD Biosciences, San Jose, CA, USA) was added to the test samples, and $20 \mu \mathrm{L}$ homologous control was added to the control samples. After incubation at room temperature for 20 minutes, $2 \mathrm{~mL}$ PBS was added, the mixture was centrifuged at $300 \mathrm{~g} / \mathrm{min}$ for 5 minutes, and the supernatant was discarded (repeated twice). The cells were resuspended with $500 \mu \mathrm{L}$ PBS and subjected to flow cytometry, and 3,000-5,000 CD3extracellular domain-gated cells were counted. Thl7 cells $\left(\mathrm{CD}^{+}, \mathrm{CD} 8^{-}, \mathrm{IL}-17^{+} \mathrm{T}\right.$ cells) were detected using a flow cytometer (Epics XL, Beckman Coulter, Brea, CA, USA; FACSCalibur, BD Biosciences) and FlowJo 8.6.2 software (Tree Star, Ashland, OR, USA).

\section{Analysis of Treg cells}

Treg cells were also detected by flow cytometry. A $50 \mu \mathrm{L}$ sample of fasting peripheral venous blood was incubated with $5 \mu \mathrm{L}$ fluorescein isothiocyanate (FITC)-labelled antiCD4 monoclonal antibody, $5 \mu \mathrm{L}$ PC5-conjugated anti$\mathrm{CD} 25$ monoclonal antibody, and $5 \mu \mathrm{L}$ PE-conjugated antiCD127 monoclonal antibody (Beyotime Biotechnology, Wuhan, China), with gentle shaking to ensure adequate mixing. Next, $600 \mu \mathrm{L}$ of a self-made erythrocyte lysis solution A was added, and the mixture was shaken until it clarified. Then, $265 \mu \mathrm{L}$ solution B was added, and the mixture was shaken. Subsequently, $2 \mathrm{~mL}$ PBS was added, and the supernatant was discarded after centrifugation for
5 minutes at $300 \mathrm{~g} / \mathrm{min}$ (repeated twice). After resuspension in $500 \mu \mathrm{L}$ PBS, 3,000-5,000 cells were counted by flow cytometry for analysis of Treg cells (Epics XL, Beckman Coulter; FACSCalibur, BD Biosciences; FlowJo 8.6.2 software, Tree Star).

\section{Statistical analysis}

Continuous measurement data are expressed as mean \pm standard deviation (SD), and enumeration data are presented as $\mathrm{n}(\%)$. Comparisons between groups were made using the rank-sum test and independent-samples $t$-test, as appropriate. Correlations between parameters were evaluated using Pearson and partial correlation analyses. A two-sided $\mathrm{P}$ value $<0.05$ was considered significant. Analyses were conducted using SPSS 16.0 (SPSS Inc., Chicago, IL, USA).

\section{Results}

\section{Baseline characteristics of the study participants}

The final analysis included 42 patients with PLF, 30 patients with hepatitis (but without liver failure), and 30 healthy control subjects. Among the 42 patients with PLF, 33 subsequently showed an improvement in their condition while 9 exhibited deterioration to overt liver failure. The baseline clinical characteristics of the study participants are summarized in Table 1. Patients with PLF had markedly higher ALT and TBil levels and lower PTA than patients with hepatitis or healthy controls.

\section{Comparison of serum IL-35 levels at enrollment between patients with PLF, patients with hepatitis, and healthy control subjects}

As shown in Figure 1, the serum level of IL-35 at enrollment was significantly higher in patients with PLF $(594.6 \pm 192.6 \mathrm{pg} / \mathrm{mL}, \mathrm{n}=42)$ than in patients with hepatitis $(143.2 \pm 47.4 \mathrm{pg} / \mathrm{mL}, \mathrm{n}=30 ; \mathrm{P}<0.001)$ or healthy controls $(60.7 \pm 18.2 \mathrm{pg} / \mathrm{mL}, \mathrm{n}=30 ; \mathrm{P}<0.001)$.

\section{Comparison of serum IL-35 level and Treg/Th17 ratio at enrollment between patients with PLF who recovered and patients with PLF who deteriorated to overt liver failure}

For further analysis of the serum IL-35 level and Treg/ Th17 ratio, patients with PLF were divided into 2 groups according to whether they showed an improvement in their 
Table 1 Baseline clinical characteristics of the study participants

\begin{tabular}{lcccc}
\hline Parameter & PLF with improvement $(n=33)$ & PLF with deterioration $(n=9)$ & Hepatitis $(n=30)$ & Healthy controls $(n=30)$ \\
\hline Male sex ${ }^{\#}$ & $26(78.8 \%)$ & $7(77.8 \%)$ & $22(73.3 \%)$ & $23(76.7 \%)$ \\
Age (years) & $43 \pm 11$ & $44 \pm 10$ & $44 \pm 14$ & $44 \pm 12$ \\
ALT $(\mathrm{U} / \mathrm{L})^{*}$ & $2,554 \pm 2,066$ & $2,644 \pm 2,334$ & $363 \pm 319$ & $24 \pm 8$ \\
TBil $(\mu \mathrm{mol} / \mathrm{L})^{*}$ & $133 \pm 25$ & $128 \pm 22$ & $41 \pm 18$ & $14 \pm 3$ \\
PTA $(\%)^{*}$ & $45 \pm 2$ & $44 \pm 3$ & $85 \pm 10$ & $95 \pm 3$ \\
Cr $(\mu \mathrm{mol} / \mathrm{L})^{*}$ & $55.27 \pm 16.61$ & $61.1 \pm 18.55$ & $54.03 \pm 17.46$ & $56.97 \pm 15.82$ \\
AFP $(\mathrm{ug} / \mathrm{L})^{*}$ & $29.17 \pm 19.53$ & $13.57 \pm 9.61$ & $6.93 \pm 5.66$ & $5.64 \pm 2.13$ \\
\hline
\end{tabular}

* represents $\mathrm{P}<0.05$; " represents $\mathrm{P}>0.05$. PLF, prophase of liver failure; ALT, alanine aminotransferase; TBil, total bilirubin; PTA, prothrombin time activity; AFP, alpha fetoprotein.

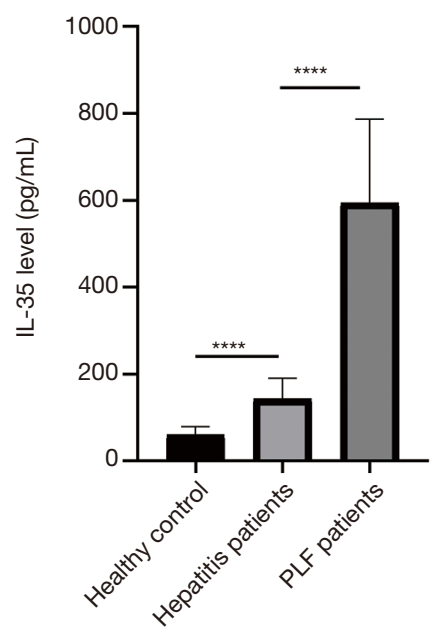

Figure 1 Comparison of serum interleukin-35 levels at enrollment between patients with prophase of liver failure $(n=42)$, patients with hepatitis $(n=30)$, and healthy control subjects $(n=30)$. Data are presented as mean \pm standard deviation. IL-35, interleukin-35; PLF, prophase of liver failure. ${ }^{* * *}, \mathrm{P}<0.001$.

condition or deterioration to overt liver failure. The serum level of IL-35 at enrollment was significantly higher in patients with PLF who showed subsequent improvement than in patients with PLF who showed subsequent deterioration $(656.6 \pm 165.2 \mathrm{pg} / \mathrm{mL}$ vs. $367.2 \pm 82.9 \mathrm{pg} / \mathrm{mL}$; $\mathrm{P}<0.001$; Figure 2). Treg and Th17 were tested by flow cytometry between the above 2 groups (Figures 3,4). The results showed that there was no difference in the percentage of Treg cells between the 2 groups, but the ratio of Treg/Th17 was significantly higher in patients with

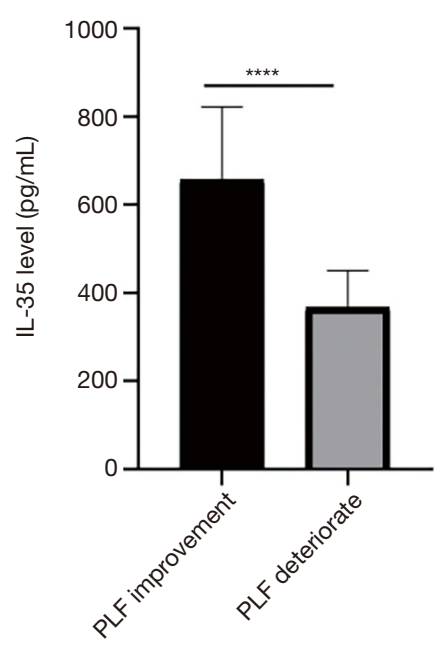

Figure 2 Comparison of serum interleukin-35 levels at enrollment between patients with prophase of liver failure who recovered (improvement group, $\mathrm{n}=33$ ) and patients with prophase of liver failure who deteriorated to overt liver failure (deteriorate group, $\mathrm{n}=9)$. Data are presented as mean \pm standard deviation. IL-35, interleukin-35. ${ }^{* * *}, \mathrm{P}<0.001$.

PLF who showed improvement than in patients with PLF who developed overt liver failure $(3.41 \pm 0.42$ vs. $2.49 \pm 0.41$; $\mathrm{P}<0.001$; Figure 5).

\section{Correlation between serum IL-35 level and Treg/Th17 ratio in patients with PLF}

The serum IL-35 level and Treg/Th17 ratio were significantly positively correlated in patients with PLF 

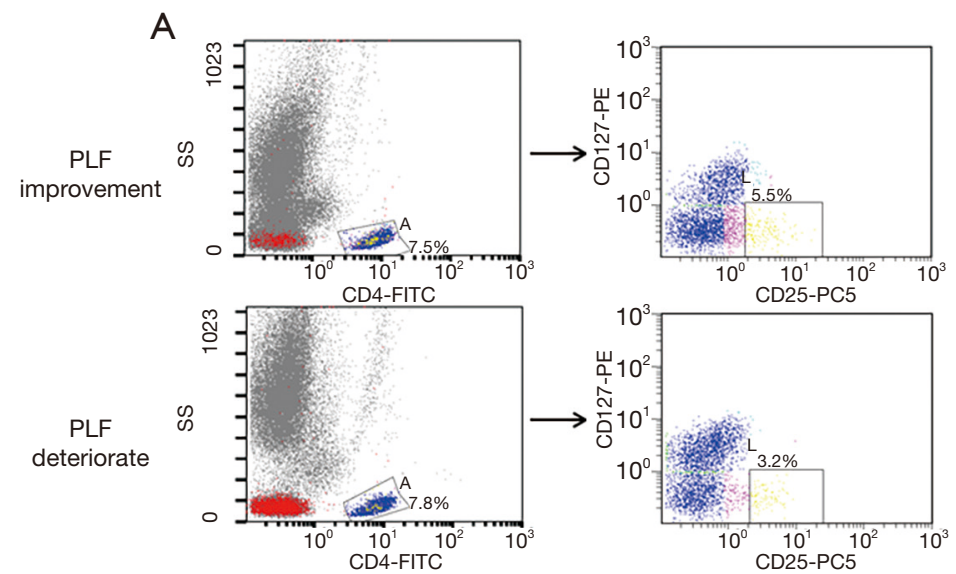

B

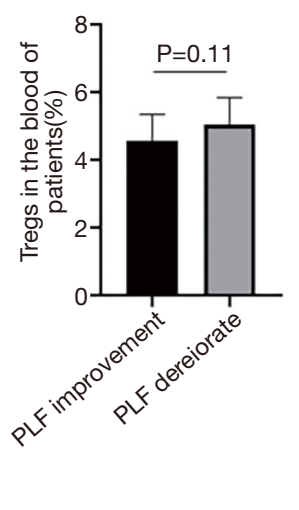

Figure 3 Treg cells between PLF improvement group and PLF deteriorate group. (A) Flow cytometry analysis of Treg cells in peripheral blood samples from PLF improvement and PLF deteriorate patients. Whole blood was centrifuged to remove plasma. The lower cells were lysed to remove red blood cells for further FACS analysis. In the FACS analysis, we first gated CD4+SSC ${ }^{\text {low }}$ cells and then analyzed CD25+CD127 $7^{\text {low }}$ cells; (B) the comparison of Treg cells between the two groups. PLF, prophase of liver failure; FACS, fluorescence activating cell sorter.

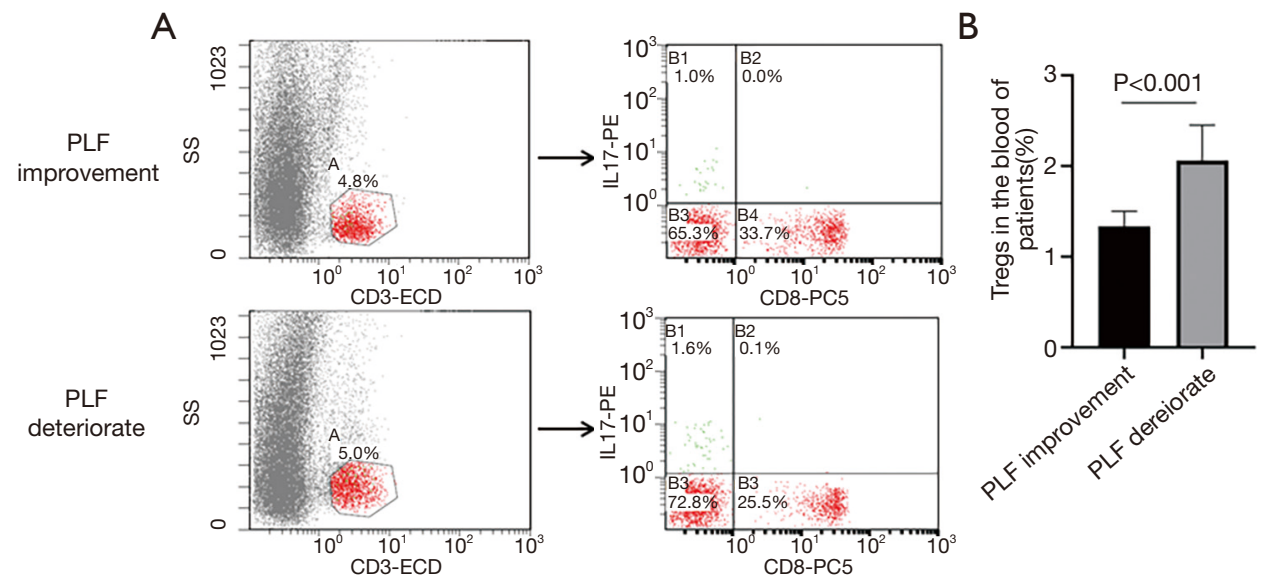

Figure 4 Th17 cells between PLF improvement group and PLF deteriorate group. (A) Flow cytometry analysis of Th17 cells in peripheral blood samples from PLF improvement and PLF deteriorate patients. Whole blood was centrifuged to remove plasma. The lower cells were lysed to remove red blood cells for further FACS analysis. In the FACS analysis, we first gated CD3+SSC ${ }^{\text {low }}$ cells and then analyzed CD8IL17+ cells; (B) the comparison of Th17 cells between the two groups. PLF, prophase of liver failure; FACS, fluorescence activating cell sorter.

$\left(\mathrm{r}^{2}=0.65 ; \mathrm{P}<0.001 ;\right.$ Figure 6).

\section{Discussion}

A notable finding of this study was that the serum IL-35 level at enrollment was significantly higher in patients with PLF than in patients with hepatitis or healthy controls. Furthermore, the serum IL-35 level was significantly higher in patients with PLF who showed subsequent improvement than in patients with PLF who showed deterioration to overt liver failure. The Treg/Th17 ratio was also significantly higher in patients with PLF who showed improvement than in patients with PLF who developed overt liver failure. In addition, the serum IL-35 level and Treg/Th17 ratio were positively correlated in patients with PLF. Our data indicate that although the serum IL-35 level 


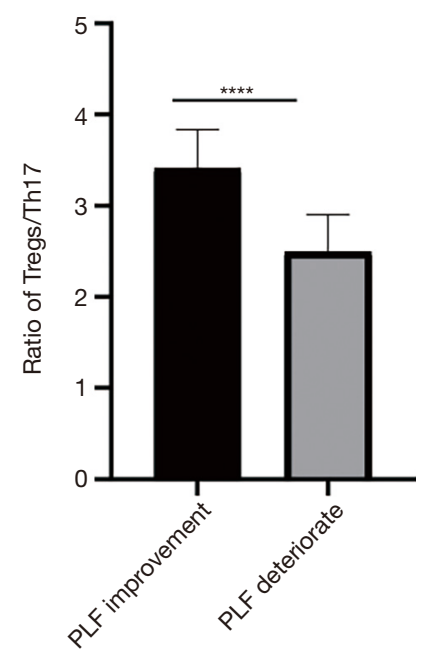

Figure 5 Comparison of the ratio of regulatory $\mathrm{T}$ cells to T-helper type-17 cells between patients with prophase of liver failure who recovered (improvement group, $n=33$ ) and patients with prophase of liver failure who deteriorated to overt liver failure (deteriorate group, $n=9$ ). Data are presented as mean \pm standard deviation. Treg/Th17, ratio of regulatory $\mathrm{T}$ cells to T-helper type-17 cells. ****, $\mathrm{P}<0.001$.

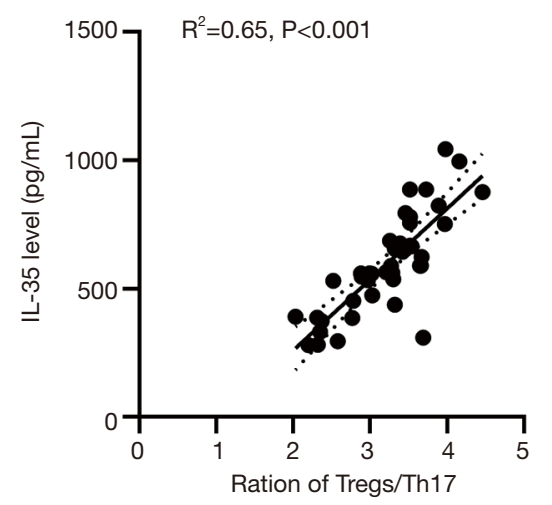

Figure 6 The relationship between serum interleukin-35 level and ratio of regulatory $T$ cells to T-helper type- 17 cells in patients with prophase of liver failure. IL-35, interleukin-35; Treg/Th17, ratio of regulatory $\mathrm{T}$ cells to $\mathrm{T}$-helper type-17 cells.

is elevated in patients with PLF, a higher level of IL-35 is associated with a better prognosis. This finding may reflect a beneficial, anti-inflammatory effect of IL-35 that acts to limit the extent of immune-mediated liver injury.

ALF arises as a consequence of a rapid decompensation of liver function and leads to clinical manifestations that include coagulation dysfunction, jaundice, hepatic encephalopathy, and ascites. The mortality rate of liver failure can be as high as $60-80 \%$, illustrating the lifethreatening nature of this disease (25). Although the pathogenesis of liver failure has yet to be fully characterized, it is generally acknowledged that immune imbalance plays an important role (26). Although the immune system functions as a complex network of cells and cytokines, Treg cells play key roles in the maintenance of immune balance through the secretion of cytokines such as IL-35 (27).

IL-35 belongs to the IL-12 cytokine family that also includes IL-12, IL-23, and IL-27 (28). IL-35 is secreted mainly by CD4+ FOXP3+ Treg cells and iTr35 Treg cells, a Treg cell population induced by IL-35. IL-35 may be the only member of the IL-12 cytokine family in humans to have the capacity to upregulate upon activation in vivo (29,30). IL-35 may be a major contributor to immunological, inflammatory, and infectious diseases, as well as tumor progression (31-34). IL-35 has 2 known biological effects in vitro and in vivo: (I) suppression of the proliferation of conventional $\mathrm{T}$ (Tconv) cells; and (II) the conversion of naive Tconv cells into a strongly suppressive induced Treg cell population (i $\operatorname{Tr} 35$ cells), which function via IL-35 (17,35). The physiological effects of IL-35 result mainly from the induction of Treg cell proliferation and expansion and the inhibition of Th17 cell differentiation, but IL-35 can also suppress CD4+ effector T cell activation leading to a reduction in all reactive T-cell responses (36). Furthermore, IL-35 overexpression results in a selective decrease in the frequency of Th1 cells and an increase in IL-10-producing CD4+ T cells. In the setting of HBV infection, serum levels of tumor necrosis factor- $\alpha$, interferon- $\gamma$, IL-6, IL-22, and IL-23 decrease while IL-10 increases in response to IL-35 (37-39).

Several studies have shown that both murine and human IL-35 can mediate infectious tolerance that may contribute to the development of chronic $\mathrm{HBV}$ and $\mathrm{HCV}$ infection $(18,20,40,41)$. This may explain previous reports that a higher level of IL-35 is associated with increased viral load, more severe disease, and poorer survival in patients with chronic hepatitis B $(19,21,42)$. On the other hand, IL-35 can help to maintain immune balance when an excessive immune response occurs in response to $\mathrm{HBV}$ infection (43-45), and this may be one mechanism by which Treg cells inhibit the progression of liver failure (46). Although overt liver failure is difficult to treat, not all patients with PLF progress to overt liver failure. Since immune balance is an important factor influencing the progression of liver failure, and because IL-35 is the most important cytokine 
secreted by Treg cells to maintain immune balance during HBV infection $(47,48)$, we evaluated whether serum levels of IL-35 were elevated in patients hospitalized with PLF. We found that the level of IL-35 was markedly higher in patients with PLF than in patients with hepatitis or healthy controls, in agreement with a previous study (49). To further examine the potential role of IL-35 in the prognosis of PLF, patients were divided into 2 groups according to their outcomes, i.e., an improvement in disease condition or progression to overt liver failure. Interestingly, the serum IL-35 level was significantly higher in patients with PLF who showed recovery than in patients with PLF who deteriorated. Based on this finding, we speculate that IL-35 is beneficial in patients with PLF, which is consistent with the conclusions of a previous study (20).

The Treg/Th17 ratio plays an important role in maintaining the balance of the immune system, and disorders of both cellular and humoral immunity are found in patients with chronic hepatitis or liver failure. Treg cells express low levels of CD127 and high levels of CD25 and the transcription factor FOXP3, and a serious imbalance of the Treg/Th17 ratio has been reported for liver failure (50). However, there is little published research regarding the changes in the Treg/Th17 ratio during PLF. We speculated that an imbalance between populations of Treg and Th17 cells also exists in patients with PLF and that IL-35 might play an important role in the regulation of the Treg/Th17 ratio in these patients. We found that the Treg/Th17 ratio was significantly higher in patients with PLF who subsequently improved than in patients who progressed to overt liver failure. Furthermore, the Treg/Th17 ratio and serum level of IL-35 were significantly positively correlated $\left(\mathrm{r}^{2}=0.65 ; \mathrm{P}<0.001\right)$. We propose that a high serum level of IL-35 is beneficial for the prognosis of patients with PLF because it shifts the Treg/Th17 cell ratio to suppress inflammation and the progression of hepatocyte necrosis, thereby protecting patients with PLF from developing liver failure $(36,51,52)$.

This study has some limitations. Our sample size was quite small, so the study may have been underpowered to detect real differences between groups, and the potential of IL-35 to be used as a biomarker for prognosis was not evaluated. In addition, the mechanisms underlying the association between IL-35 level and prognosis were not directly investigated. Additional studies are needed to confirm our results and validate serum IL-35 level as a prognostic marker.

\section{Conclusions}

In conclusion, serum IL-35 level is elevated in patients with PLF, but a higher level is associated with a better prognosis (i.e., recovery rather than progression to overt liver failure). We suggest that IL-35 may exert a beneficial, anti-inflammatory action that limits the extent of immunemediated liver injury. Additional prospective studies with serial measurements of the serum IL-35 level are warranted to compare changes in IL-35 over time between patients with PLF that recover and those that develop overt liver failure. Furthermore, regression analyses and receiver operating characteristic curve analyses are needed to validate serum IL-35 level as a prognostic biomarker. An additional objective for future research will be to establish whether IL-35 might be a new therapeutic target for the design of novel treatments that suppress the progression of PLF to overt liver failure.

\section{Acknowledgments}

Funding: This work was supported by grants from the National Science and Technology "13th Five-Year Plan" Major Special Project (2017ZX110203201) and Suzhou Science and Education Xingwei Youth Science and Technology Project (2019001308030004, KJXW2018004).

\section{Footnote}

Reporting Checklist: The authors have completed the STROBE reporting checklist. Available at https://dx.doi. org/10.21037/apm-21-1680

Data Sharing Statement: Available at https://dx.doi. org/10.21037/apm-21-1680

Conflicts of Interest: All authors have completed the ICMJE uniform disclosure form (available at https://dx.doi. org/10.21037/apm-21-1680). The authors have no conflicts of interest to declare.

Ethical Statement: The authors are accountable for all aspects of the work in ensuring that questions related to the accuracy or integrity of any part of the work are appropriately investigated and resolved. All procedures performed in this study involving human participants were in accordance with the Declaration of Helsinki (as revised in 2013). The study was approved by Medical ethics 
committee of the First Affiliated Hospital of Soochow University [No.: 175(2021)] and informed consent was taken from all the patients.

Open Access Statement: This is an Open Access article distributed in accordance with the Creative Commons Attribution-NonCommercial-NoDerivs 4.0 International License (CC BY-NC-ND 4.0), which permits the noncommercial replication and distribution of the article with the strict proviso that no changes or edits are made and the original work is properly cited (including links to both the formal publication through the relevant DOI and the license). See: https://creativecommons.org/licenses/by-nc-nd/4.0/.

\section{References}

1. Grek A, Arasi L. Acute Liver Failure. AACN Adv Crit Care 2016;27:420-9.

2. Montrief T, Koyfman A, Long B. Acute liver failure: A review for emergency physicians. Am J Emerg Med 2019;37:329-37.

3. Lefkowitch JH. The Pathology of Acute Liver Failure. Adv Anat Pathol 2016;23:144-58.

4. Stravitz RT, Lee WM. Acute liver failure. Lancet 2019;394:869-81.

5. Bernal W, Lee WM, Wendon J, et al. Acute liver failure: A curable disease by 2024? J Hepatol 2015;62:S112-20.

6. Mobley CM, Saharia A. Management of the critically ill liver failure patient: surpassing our limitations to reach transplantation. Curr Opin Organ Transplant 2018;23:145-50.

7. Cai J, Wang K, Han T, et al. Evaluation of prognostic values of inflammation-based makers in patients with HBV-related acute-on-chronic liver failure. Medicine (Baltimore) 2018;97:e13324.

8. Cai YJ, Dong JJ, Dong JZ, et al. A nomogram for predicting prognostic value of inflammatory response biomarkers in decompensated cirrhotic patients without acute-on-chronic liver failure. Aliment Pharmacol Ther 2017;45:1413-26.

9. Fan Z, EnQiang C, Yao DL, et al. Neutrophil-lymphocyte ratio predicts short term mortality in patients with hepatitis B virus-related acute-on-chronic liver failure treated with an artificial liver support system. PLoS One 2017;12:e175332.

10. Gong J, Zhou W, Xiao C, et al. A nomogram for predicting prognostic value of inflammatory biomarkers in patients with acute-on-chronic liver failure. Clin Chim
Acta 2018;478:7-12.

11. Grønbæk H, Rodgaard-Hansen S, Aagaard NK, et al. Macrophage activation markers predict mortality in patients with liver cirrhosis without or with acute-onchronic liver failure (ACLF). J Hepatol 2016;64:813-22.

12. Jiang SW, Wang P, Xiang XG, et al. Serum soluble ST2 is a promising prognostic biomarker in HBV-related acuteon-chronic liver failure. Hepatobiliary Pancreat Dis Int 2017;16:181-8.

13. Song $M, M a X$. The Immunobiology of Interleukin-35 and Its Regulation and Gene Expression. Adv Exp Med Biol 2016;941:213-25.

14. Zhang J, Zhang Y, Wang Q, et al. Interleukin-35 in immune-related diseases: protection or destruction. Immunology 2019;157:13-20.

15. Bello RO, Chin VK, Abd Rachman Isnadi MF, et al. The Role, Involvement and Function(s) of Interleukin-35 and Interleukin-37 in Disease Pathogenesis. Int J Mol Sci 2018;19:1149.

16. Zheng XF, Hu XY, Ma B, et al. Interleukin-35 Attenuates D-Galactosamine/Lipopolysaccharide-Induced Liver Injury via Enhancing Interleukin-10 Production in Kupffer Cells. Front Pharmacol 2018;9:959.

17. Li X, Tian L, Dong Y, et al. IL-35 inhibits HBV antigenspecific IFN-gamma-producing CTLs in vitro. Clin Sci (Lond) 2015;129:395-404.

18. Liu S, Zhang Q, Shao X, et al. An immunosuppressive function of interleukin-35 in chronic hepatitis $\mathrm{C}$ virus infection. Int Immunopharmacol 2017;50:87-94.

19. Shi YY, Dai MJ, Wu GP, et al. Levels of interleukin-35 and its relationship with regulatory T-cells in chronic hepatitis B patients. Viral Immunol 2015;28:93-100.

20. Teng DK, Liu Y, Lv YF, et al. Elevated interleukin-35 suppresses liver inflammation by regulation of $\mathrm{T}$ helper 17 cells in acute hepatitis B virus infection. Int Immunopharmacol 2019;70:252-9.

21. Zhou Y, Zhang H, Li Y. IL-35 expression in peripheral blood CD4(+) T cells from chronic hepatitis B virusinfected patients directly correlates with virus load. Cytokine 2015;73:169-75.

22. Fu YP, Yi Y, Cai XY, et al. Overexpression of interleukin-35 associates with hepatocellular carcinoma aggressiveness and recurrence after curative resection. Br J Cancer 2016;114:767-76.

23. Qiu X, Wang X, Song Y, et al. Plasma Level of Interleukin-35 as an Independent Prognostic Indicator in Hepatocellular Carcinoma. Dig Dis Sci 2016;61:3513-21. 24. Yang L, Shao X, Jia S, et al. Interleukin-35 Dampens 
CD8(+) T Cells Activity in Patients With Non-viral Hepatitis-Related Hepatocellular Carcinoma. Front Immunol 2019;10:1032.

25. European Association for the Study of the Liver. EASL 2017 Clinical Practice Guidelines on the management of hepatitis B virus infection. J Hepatol 2017;67:370-98.

26. Langhans B, Braunschweiger I, Arndt S, et al. Corespecific adaptive regulatory T-cells in different outcomes of hepatitis C. Clin Sci (Lond) 2010;119:97-109.

27. Karkhah A, Javanian M, Ebrahimpour S. The role of regulatory $\mathrm{T}$ cells in immunopathogenesis and immunotherapy of viral infections. Infect Genet Evol 2018;59:32-7.

28. Collison LW, Workman CJ, Kuo TT, et al. The inhibitory cytokine IL-35 contributes to regulatory T-cell function. Nature 2007;450:566-9.

29. Collison LW, Chaturvedi V, Henderson AL, et al. IL35-mediated induction of a potent regulatory $\mathrm{T}$ cell population. Nat Immunol 2010;11:1093-101.

30. Collison LW, Delgoffe GM, Guy CS, et al. The composition and signaling of the IL-35 receptor are unconventional. Nat Immunol 2012;13:290-9.

31. Chen Y, Wang CJ, Lin SH, et al. Interleukin-35 is upregulated in response to influenza virus infection and secondary bacterial pneumonia. Cytokine 2016;81:23-7.

32. Sakkas LI, Mavropoulos A, Perricone C, et al. IL-35: a new immunomodulator in autoimmune rheumatic diseases. Immunol Res 2018;66:305-12.

33. Wang RX, Yu CR, Dambuza IM, et al. Interleukin-35 induces regulatory B cells that suppress autoimmune disease. Nat Med 2014;20:633-41.

34. Wang Z, Liu JQ, Liu Z, et al. Tumor-derived IL35 promotes tumor growth by enhancing myeloid cell accumulation and angiogenesis. J Immunol 2013;190:2415-23.

35. Tao L, Zhu J, Chen Y, et al. IL-35 improves Tregmediated immune suppression in atherosclerotic mice. Exp Ther Med 2016;12:2469-76.

36. Hu Y, Dong C, Yue Y, et al. In vivo delivery of interleukin-35 relieves coxsackievirus-B3-induced viral myocarditis by inhibiting Th17 cells. Arch Virol 2014;159:2411-9.

37. Huang Q, Wang Y, Si C, et al. Interleukin-35 Modulates the Imbalance Between Regulatory T Cells and T Helper 17 Cells in Enterovirus 71-Induced Hand, Foot, and Mouth Disease. J Interferon Cytokine Res 2017;37:522-30.

38. Huang Y, Hu H, Liu L, et al. Interleukin-12p35 Deficiency
Reverses the Th1/Th2 Imbalance, Aggravates the Th17/ Treg Imbalance, and Ameliorates Atherosclerosis in ApoE/- Mice. Mediators Inflamm 2019;2019:3152040.

39. Nikoopour E, Bellemore SM, Singh B. IL-22, cell regeneration and autoimmunity. Cytokine 2015;74:35-42.

40. Chaturvedi V, Collison LW, Guy CS, et al. Cutting edge: Human regulatory $\mathrm{T}$ cells require IL-35 to mediate suppression and infectious tolerance. J Immunol 2011;186:6661-6.

41. Jung MK, Shin EC. Regulatory T Cells in Hepatitis B and C Virus Infections. Immune Netw 2016;16:330-6.

42. Yu X, Guo R, Ming D, et al. The Transforming Growth Factor beta1/Interleukin-31 Pathway Is Upregulated in Patients with Hepatitis B Virus-Related Acute-on-Chronic Liver Failure and Is Associated with Disease Severity and Survival. Clin Vaccine Immunol 2015;22:484-92.

43. Boeijen LL, Hoogeveen RC, Boonstra A, et al. Hepatitis B virus infection and the immune response: The big questions. Best Pract Res Clin Gastroenterol 2017;31:265-72.

44. Cheng ST, Yuan D, Liu Y, et al. Interleukin-35 Level Is Elevated in Patients with Chronic Hepatitis B Virus Infection. Int J Med Sci 2018;15:188-94.

45. Xia Y, Protzer U. Control of Hepatitis B Virus by Cytokines. Viruses 2017;9:18.

46. Yang L, Jia S, Shao X, et al. Interleukin-35 modulates the balance between viral specific CD4(+)CD25(+) CD127(dim/-) regulatory $\mathrm{T}$ cells and $\mathrm{T}$ helper 17 cells in chronic hepatitis B virus infection. Virol J 2019;16:48.

47. Liang XS, Li CZ, Zhou Y, et al. Changes in circulating Foxp3(+) regulatory $T$ cells and interleukin-17producing $\mathrm{T}$ helper cells during HBV-related acuteon-chronic liver failure. World J Gastroenterol 2014;20:8558-71.

48. Niu YH, Yin DL, Liu HL, et al. Restoring the Treg cell to Th17 cell ratio may alleviate HBV-related acute-on-chronic liver failure. World J Gastroenterol 2013;19:4146-54.

49. Xiang XG, Xie Q. IL-35: a potential therapeutic target for controlling hepatitis B virus infection. J Dig Dis 2015;16:1-6.

50. Wang Q, Zheng Y, Huang Z, et al. Activated IL-23/IL-17 pathway closely correlates with increased Foxp3 expression in livers of chronic hepatitis B patients. BMC Immunol 2011;12:25.

51. Niu Y, Liu H, Yin D, et al. The balance between 
intrahepatic IL-17(+) T cells and Foxp3(+) regulatory T cells plays an important role in HBV-related end-stage liver disease. BMC Immunol 2011;12:47.

52. Zongyi $Y$, Funian $Z$, Hao L, et al. Interleukin-35 mitigates the function of murine transplanted islet cells via regulation of Treg/Th17 ratio. PLoS One 2017;12:e0189617.

(English Language Editor: C. Betlazar-Maseh)

Cite this article as: Chen L, Sun W, Wang Y, Huang X, Gan J. Lower levels of interleukin-35 in patients with prophase of liver failure are associated with progression to liver failure. Ann Palliat Med 2021;10(8):9174-9183. doi: 10.21037/apm-21-1680 